\title{
Burden of family caregivers of ophthalmic patients in a university teaching hospital in south-west Nigeria
}

\section{Samuel A. Olowookere ${ }^{1}$, Sarat A. Badmus ${ }^{2}$, Olajumoke Laoye ${ }^{3}$, Macellina}

\section{Y. Ijadunola ${ }^{1}$, Mustapha Hassan ${ }^{4}$}

1. Department of Community Health, Obafemi Awolowo University, Ile-Ife, Nigeria

2. Department of Ophthalmology, Obafemi Awolowo University, Ile-Ife, Nigeria

3. Department of Ophthalmology, Obafemi Awolowo University Teaching Hospitals Complex,Ile-Ife, Nigeria

4. Department of Ophthalmology, Osun State University, Osogbo, Nigeria

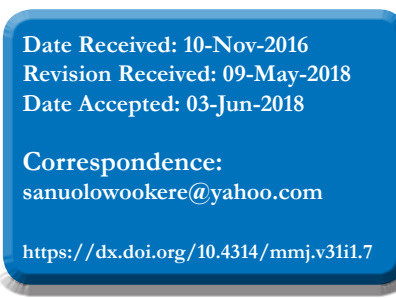

\section{Abstract}

\section{Background}

The family provides support in the care of their ill members and suffers some burden during caregiving. This study assessed the burden of family caregivers and associated factors in an ophthalmic clinic situated in a university teaching hospital in southwest Nigeria.

Methods

This was a descriptive cross-sectional study where consenting family caregivers of ophthalmic patients completed a semi-structured questionnaire containing information on their socio-demographic characteristics and caregiving burden using the Zarit burden interview. Descriptive and inferential statistics analyses were done.

Results

A total of 273 caregivers completed the study. The caregivers were parents $(23.5 \%)$, spouses $(20.1 \%)$, siblings $(3.3 \%)$, children $(35.9 \%)$ and other relatives $(14.2 \%)$ with mean age (SD) of 38.9 (14.9) years (range 8-79 years). Majority (81.2\%) experienced caregiver burden with prayer $(89 \%)$ as a coping strategy. Financial support $(56 \%)$ was a major caregiver need with majority (59.3\%) satisfied with their relatives' hospital care. Neither the patients nor their caregivers were on health insurance scheme. Statistical significant factors associated with caregivers' burden included young age $(\mathrm{AOR}=4.63,95 \% \mathrm{CI}=1.55-13.90 ; \mathrm{p}=0.01)$, higher education $(\mathrm{AOR}=5.51,95 \% \mathrm{CI}=2.30-13.2$, $\mathrm{p}=0.01)$, being employed $(\mathrm{AOR}=1.72,95 \mathrm{CI}=1.30-4.76, \mathrm{p}=0.04)$, longer caregiving $(\mathrm{AOR}=3.37,95 \% \mathrm{CI}=1.27-7.02$, $\mathrm{p}=0.02)$, and having patient on hospital admission $(\mathrm{AOR}=1.90,95 \% \mathrm{CI}=1.26-3.09, \mathrm{p}=0.02)$.

Conclusion

Family caregivers of ophthalmic patients experienced significant burden. Hence, they need more assistance from the health care institutions and community, including policy makers, so that they can cope with their caregiving activities. Enrollment in the social health insurance scheme will reduce out of pocket payment of hospital bills.

Keywords: family caregivers; burden, ophthalmic patients

\section{Introduction}

Patients with eye diseases face several hardships and mostly depend on their family members for support in order to cope with this state of near destitution. ${ }^{1}$ Vision disorders are a major public health problem as they cause disability, suffering and loss of productivity. Patients with vision disorders have to depend on their family members for the activities of daily living as they are unable to fend for themselves. Hence, there is positive correlation between lower socio-economic status and blindness. ${ }^{2}$ A family caregiver is a family member that lives with the patients and is closely involved in their activities of daily living, health care and relates socially with them $^{3}$. Burden is the presence of problems, difficulties, and adverse effects affecting the lives of the caregivers. ${ }^{3}$

While caring for these patients, caregivers sometimes neglect their own physical and emotional needs. The caregiver experiences, while providing care, most times strain the most competent person. ${ }^{4}$ Many caregivers, though employed, have to care for their relative with eye disease with some reporting role conflict requiring re-arranging their work schedule without notice, working for fewer than normal hours or having to stop working while caring for their ill relatives. ${ }^{1}$ This reduces their financial capability as they are less concerned about themselves while caring. ${ }^{3}$ These negative experiences had been shown to lead to frustration, anxiety, fear, guilt feeling, depression and, sometimes, grief. ${ }^{1}$

The World Health Organization (WHO) defines caregiver burden as "the emotional, physical, financial demands and responsibilities of an individual's illness that are placed on the family members, friends or other individuals involved with the individual outside the health care system." ${ }^{1,3}$ The effect of stress on family caregivers has been referred to as caregiver's burden. ${ }^{5,6}$ Eye diseases place a considerable burden on family caregivers as they care for their relatives. ${ }^{1}$ 
This study was conducted to provide information on caregiving experiences of family caregivers of patients living with eye diseases in order for health workers to plan and implement a comprehensive treatment programme targeting such cases. This will enhance the quality of life of these patients and their family caregivers. Therefore, this study assessed the burden of family caregivers and associated factors in an ophthalmic clinic situated in a major university teaching hospital in south-west Nigeria.

\section{Methods}

This was a descriptive cross-sectional study conducted over a period of three months from January to March, 2016, at an ophthalmic clinic of the Department of Ophthalmology of the Obafemi Awolowo University Teaching Hospitals Complex, Ile-Ife, Nigeria. The Department of Ophthalmology is staffed by a team of consultant ophthalmologists, optometrists, ophthalmic nurses and other trained support staff. The clinic runs every day from 8:00 am to 4:00 pm, Monday through Friday, while emergencies are attended to on a 24-hour basis. Patients that have ophthalmic surgery are admitted into the ward. About 800-1000 patients are attended to monthly in the clinic with $5 \%$ on hospital admission. Out of these patients, about $10 \%$ are children. Our clinic records shows that common eye disease presentation includes cataract $(20 \%)$, glaucoma $(13 \%)$, refractive errors $(22 \%)$, retina and posterior segment diseases $(10 \%)$, trauma $(9 \%)$, and infections $(10 \%)$, among others.

The sample size of 223 was calculated using the appropriate statistical formula for descriptive health studies ( $n=Z^{2} p q /$ $\left.\mathrm{d}^{2}\right)^{7}$ where $82.4 \%$ family caregivers experienced caregiving burden. ${ }^{8}$ A total of 273 family caregivers were recruited in this study after non-responders were taken into consideration.

Caregivers who were adults aged 18 years and above who were family members or friends of ophthalmic patients found providing unpaid care for the patients were included in the study after informing them of the purpose of the study and taking a written consent. These consenting family caregivers were interviewed using a pretested semistructured questionnaire including information on their socio-demographic characteristics, the Zarit burden index, and their coping strategies while caring for their relatives.

The Zarit burden index is widely accepted as a reliable and valid scale for measuring caregivers' burden and has been used extensively. The index is a 22 -item index with scores ranging from 0 to 88 . The score is interpreted as little or no burden (0-21), mild to moderate burden (21-40), moderate to severe burden (41-60), and severe burden (61-88). Scores of 0-21 are taken as low burden and above 21 as high burden. It is unique as it measures various aspects of caregivers' burden such as caregivers' health, psychological well-being, finances, social life, and the relationship between the caregiver and the patient. This scale is highly reliable as documented by 0.91 internal consistency and 0.71 test-retest reliability. ${ }^{7}$

The questionnaire was translated to Yoruba, the prevalent language spoken at the study area and back-translated to English before administration. Previous studies in Nigeria have validated the Zarit burden index. ${ }^{8,9}$
The family caregivers were recruited consecutively at the clinic once they consented after the purpose of the study had been explained to them. Family caregivers whose relatives were on hospital admission for ophthalmic problems or surgery were also approached, recruited and interviewed. All consenting caregivers were serially recruited and individually interviewed in a place of their choice with privacy within the hospital, with each interview lasting about 30 minutes. None of the family caregivers declined participation in this study.

The data obtained were analysed using Statistical Package for Social Science (SPSS) version 20 (SPSS Inc., Chicago, IL, U.S.A.). Simple descriptive and inferential statistics were done. Descriptive statistics were done with results presented with frequencies, proportions, mean and standard deviations. Bivariate chi-square test was used to test associations between caregiver characteristics and caregivers' burden. Logistics regression analysis was performed to evaluate socio-demographic variables and other variables which were independently associated with caregivers' burden. Odd ratio (OR) and 95\% CI were presented and used as measures of the strength of association. Significant level was put at $p$ $<0.05$.

Ethical considerations included taking written informed consent from the study participants while they were reassured of the confidentiality of the information obtained. Permission to conduct the study was obtained from the hospital authorities while ethical clearance was approved by the Osun State Hospitals Ethics and Research Committee with protocol number SHO/ERC/06/0013. Data collected were kept in a password-protected computer.

\section{Results}

A total of 273 caregivers participated in the study. The caregivers were parents $(23.5 \%)$, spouses $(20.1 \%)$, siblings $(3.3 \%)$, children $(35.9 \%)$ and other relatives $(14.2 \%)$ with mean age of 38.9 (14.9) years (range 8-79 years). Most (56\%) caregivers were young (below 40 years), female (61.9\%), had higher education (64\%), were Christian (79.1\%), were employed $(75.5 \%)$ and earned below Nigerian minimum wage $(18,000$ Naira $\approx U S \$ 50)$ (Table 1$)$.

Table 2 shows the caregivers' feelings about their relatives' illness, other variables and effects of caregiving. Most caregivers were sad $(89 \%)$ or worried $(83.5 \%)$ about their relatives' ill health, spent 24 hours daily caring for their sick relatives $(65.5 \%)$ with majority experiencing financial difficulties (93.8\%). Majority (81.2\%) experienced caregiver burden with prayer $(89 \%)$ as a coping strategy. Financial support $(56 \%)$ was a major caregiver need with $59.3 \%$ satisfied with their relatives' hospital care. Neither the patients nor their caregivers were on health insurance scheme as the prevalent method of payment of hospital bills among the respondents was out of pocket payment. 


\begin{tabular}{|c|c|c|}
\hline Variable & Frequency $(\mathrm{N}=273)$ & $\%$ \\
\hline Primary caregiver & & \\
\hline Children & 98 & 35.9 \\
\hline 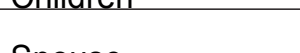 & 55 & 20.1 \\
\hline Spouse & 44 & 16.2 \\
\hline Wower & 28 & 10.3 \\
\hline Father & 9 & 3.3 \\
\hline $\begin{array}{l}\text { Sibling } \\
\text { Relative }\end{array}$ & 39 & 14.2 \\
\hline Age group (years) & & \\
\hline$<18$ & 16 & 6.0 \\
\hline $18-29$ & 62 & 22.8 \\
\hline $30-39$ & 75 & 28.2 \\
\hline $40-49$ & 48 & 17.4 \\
\hline $50-59$ & 40 & 14.8 \\
\hline $60-69$ & 21 & 7.4 \\
\hline 70 and above & 11 & 3.4 \\
\hline Sex & & \\
\hline Male & 104 & 38.1 \\
\hline & 169 & 61.9 \\
\hline $\begin{array}{l}\text { Highest level of } \\
\text { education }\end{array}$ & & \\
\hline None & 43 & 15.7 \\
\hline Primary & 55 & 20.3 \\
\hline Secondary & 72 & 26.4 \\
\hline Tertiary & 103 & 37.6 \\
\hline Occupation & & \\
\hline Unemployed & 67 & 24.5 \\
\hline Civil servant & 74 & 27.1 \\
\hline Trading & 77 & 28.4 \\
\hline Artisan & 39 & 14.2 \\
\hline Health worker & 16 & 5.8 \\
\hline Income (Naira) & 67 & 215 \\
\hline None & $6 /$ & 24.5 \\
\hline$<18,000(\approx U S \$ 50)$ & 101 & 37.0 \\
\hline$\geq 18,000(\approx U S \$ 50)$ & 105 & 38.5 \\
\hline Religion & & \\
\hline Christianity & 216 & 79.1 \\
\hline Islam & 52 & 19.0 \\
\hline Traditional & 5 & 1.9 \\
\hline
\end{tabular}

Table 2: Caregivers' feelings about relatives' illness, other variables and effects of caregiving

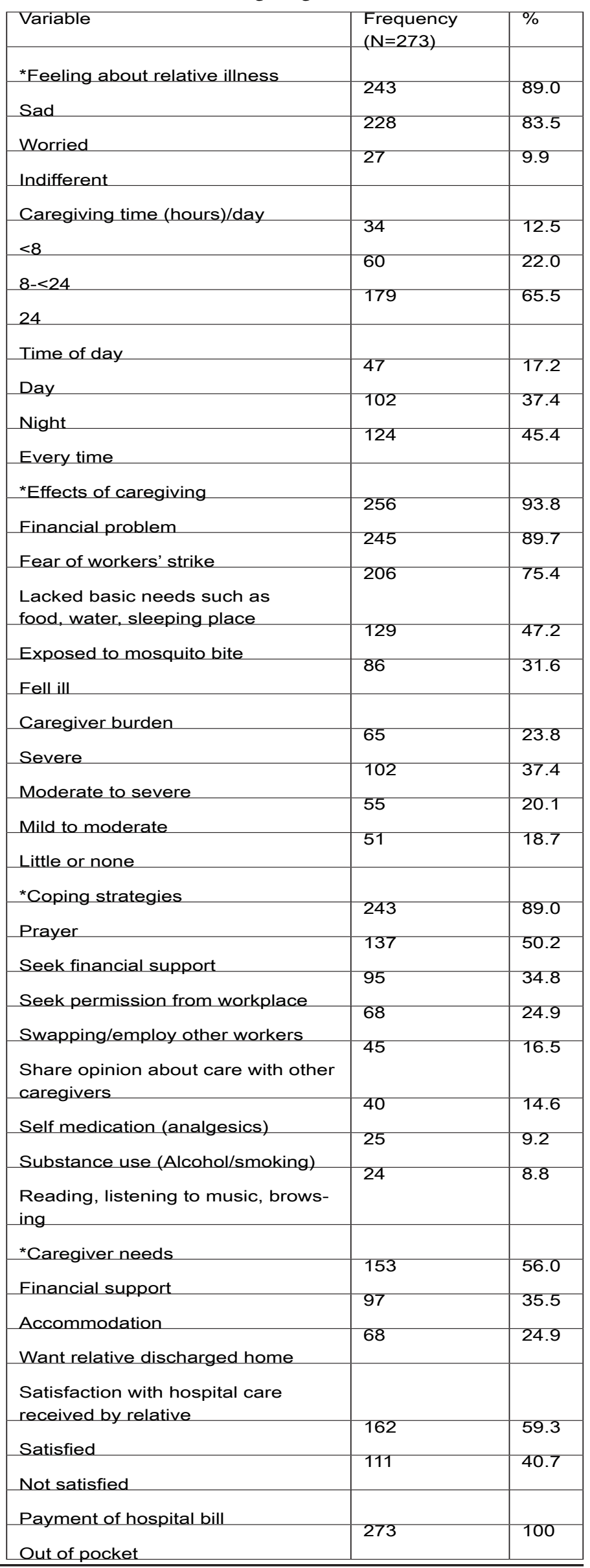


Table 3 reports factors associated with caregiver burden. These statistically significant factors include young age, higher education, being employed, longer caregiving time (24 hours every day), caring every time, and having patient admitted $(\mathrm{p}<0.05)$.

Table 3: Relationship between caregiver characteristics and caregiver burden

\begin{tabular}{|c|c|c|c|}
\hline $\begin{array}{l}\text { Caregiver } \\
\text { characteristics }\end{array}$ & \multicolumn{2}{|c|}{ Caregiver burden } & $\begin{array}{l}\text { Test statistic } \\
x^{2} ; p \text {-value }\end{array}$ \\
\hline Caregiver status & & & \\
\hline & $17(23.6)$ & $55(76.4)$ & $1.564 ; 0.21$ \\
\hline Other relatives & $34(16.9)$ & $\begin{array}{l}167 \\
(83.1)\end{array}$ & \\
\hline Age group (years) & & & \\
\hline$<40$ & & $\begin{array}{l}140 \\
(91.5)\end{array}$ & $23.766 ; 0.01$ \\
\hline$\geq 40$ & $38(31.7)$ & $82(68.3)$ & \\
\hline Sex & & & \\
\hline Male & $12(11.5)$ & $92(88.5)$ & $5.642 ; 0.02$ \\
\hline Female & $39(23.1)$ & $\begin{array}{l}130 \\
(76.9)\end{array}$ & \\
\hline $\begin{array}{l}\text { Highest level of } \\
\text { education }\end{array}$ & & & \\
\hline None/primary & $33(33.7)$ & $65(66.3)$ & $22.619 ; 0.01$ \\
\hline Secondary and above & $18(10.3)$ & $\begin{array}{l}157 \\
(89.7)\end{array}$ & \\
\hline Employment status & & & \\
\hline Unemployed & $21(31.3)$ & $46(68.7)$ & $9.3 / 1 ; 0.01$ \\
\hline Employed & $30(14.6)$ & $\begin{array}{l}176 \\
(85.4)\end{array}$ & \\
\hline Income (Naira) & & & \\
\hline Low $(<18,000 \approx$ US $\$ 50)$ & $27(16.1)$ & $\begin{array}{l}141 \\
(83.9)\end{array}$ & $1.959 ; 0.16$ \\
\hline High $(\geq 18,000 \approx$ US $\$ 50)$ & $24(22.9)$ & $81(77.1)$ & \\
\hline $\begin{array}{l}\text { Caregiving time (hours)/ } \\
\text { day }\end{array}$ & & & \\
\hline$<8$ & $12(35.3)$ & $22(64.7)$ & $14.669 ; 0.01$ \\
\hline $8-<24$ & $17(28.3)$ & $43(71.7)$ & \\
\hline 24 & $22(12.3)$ & $\begin{array}{l}157 \\
(87.7)\end{array}$ & \\
\hline Time of day & & & \\
\hline Day & $16(34)$ & $31(66)$ & $23.583 ; 0.01$ \\
\hline Night & $27(26.5)$ & $75(73.5)$ & \\
\hline Every time & $8(6.5)$ & $\begin{array}{l}116 \\
(93.5)\end{array}$ & \\
\hline $\begin{array}{l}\text { Patient's admission } \\
\text { status }\end{array}$ & & & \\
\hline Admitted & $9(8.3)$ & $\begin{array}{l}100 \\
(91.7)\end{array}$ & $12.979 ; 0.01$ \\
\hline Not admitted & $42(25.6)$ & $\begin{array}{l}122 \\
(74.4)\end{array}$ & \\
\hline
\end{tabular}

Table 4 shows logistic regression analysis of factors associated with caregiver burden. These statistically significant factors include young age $(\mathrm{AOR}=4.63,95 \% \mathrm{CI}=1.55-13.90 ; \mathrm{p}=0.01)$, higher education $(\mathrm{AOR}=5.51,95 \% \mathrm{CI}=2.30-13.2, \mathrm{p}=0.01)$, being employed (AOR $=1.72,95 \mathrm{CI}=1.30-4.76, \mathrm{p}=0.04)$, longer caregiving $(\mathrm{AOR}=3.37,95 \% \mathrm{CI}=1.27-7.02, \mathrm{p}=0.02)$ and having patient on hospital admission (AOR $=1.90$, $95 \% \mathrm{CI}=1.26-3.09, \mathrm{p}=0.02$ ).

Table 4: Logistic regression analysis of factors associated with caregiver burden

\begin{tabular}{|c|c|c|}
\hline Variable & Crude OR, $95 \% \mathrm{Cl}$, $\mathrm{p}$-value & Adjusted OR, $95 \% \mathrm{Cl}, \mathrm{p}$-value \\
\hline Age group (years) & & \\
\hline$<40$ & $4.99,2.51-9.91,0.01$ & $4.63,1.55-13.90,0.01$ \\
\hline$\geq 40$ (ref) & 1 & \\
\hline Sex & & \\
\hline Male & $2.30,1.14-4.63,0.02$ & $1.60,0.02-1.78,0.08$ \\
\hline Female (ref) & 1 & 1 \\
\hline Level of education & & \\
\hline None/primary (ref) & 1 & 1 \\
\hline $\begin{array}{l}\text { Secondary and } \\
\text { above }\end{array}$ & $4.42,2.33-8.40,0.01$ & $5.51,2.30-13.20,0.01$ \\
\hline Employment & 1 & \\
\hline Unemployed (ref) & & \\
\hline Employed & $2.68,1.40-5.10,0.01$ & $1.72,1.30-4.76,0.04$ \\
\hline Income (Naira) & $=501000$ & 00 \\
\hline $\operatorname{Low}(<18,000)$ & $1.55,0.84-2.80,0.16$ & $1.03,0.49-2.16,0.93$ \\
\hline High $(\geq 18,000)$ (ref) & & \\
\hline $\begin{array}{l}\text { Caregiving } \\
\text { time (hours)/day }\end{array}$ & 1 & \\
\hline$<8$ (ref) & $02130=7000$ & \\
\hline $8-<24$ & $2.82,1.38-5.78,0.01$ & $1.23,0.31-5.83,0.67$ \\
\hline 24 & $3.89,1.69-8.93,0.01$ & $3.37,1.27-7.02,0.02$ \\
\hline $\begin{array}{l}\text { Patient's admission } \\
\text { status }\end{array}$ & & \\
\hline Not admitted (ref) & $700 x-4$ & \\
\hline Admitted & $3.83,1.78-8.24,0.01$ & $1.90,1.26-3.09,0.02$ \\
\hline
\end{tabular}

\section{Discussion}

This study revealed that family caregivers of ophthalmic patients experienced burden while caring for their relatives at the ophthalmic clinic and ward situated in a major university teaching hospital in south-west Nigeria. The finding agrees with previous studies on caregiving and indicates the need to care for these family caregivers as caregivers wellbeing has become a focus and concern to reduce the burden they face and prevent burn out. ${ }^{10-14}$ 
Most caregivers were parents, children or spouses of these patients. This further shows that close family members provide necessary and basic care for their first degree relatives. Our findings that most caregivers were young and female are supported by various studies on caregiving. ${ }^{14-16}$ Most caregivers had higher education and were employed but earned below minimum wage. This finding is a reflection of the community in which this study took place where the level of education does not ensure appropriate employment and income. This shows the need for economic empowerment and financial support for these caregivers.

Majority of the caregivers were sad and worried about their relatives' ill health. Several studies on caregiving in chronic diseases such as cancer had reported similar findings. ${ }^{1,14,15}$ This implies that routine screening for depression is required, targeting family caregivers of ill patients.

These caregivers spent most times caring for their sick relatives and experienced financial difficulties. Therefore, it is not surprising that most caregivers suffer caregiver burden. This finding implies that to prevent burn out, there is urgent need for financial support, empowerment and relief for these caregivers. Also, the fact that these caregivers pray as a coping strategy shows the role of spirituality in reducing caregivers' burden and preventing burnout. ${ }^{13,14}$

Since financial support was a major caregiver need of these caregivers with majority expressing satisfaction with their relatives' hospital care, it suggests that finance hinders caregiving. Therefore, it reinforces the need for financial empowerment and support. Patients and their family caregivers should be educated on the need to enroll in the social health insurance scheme as this will drastically reduce out of pocket payment of hospital bills. Also, more focus should be directed towards preventive eye care through preventive education, early diagnosis and treatment. ${ }^{17}$

Factors associated with caregiver burden included young age, higher education, being employed, longer caregiving time (24 hours per day) and caring every time, and having patient admitted. These findings should be taken into consideration in formulating and directing policy to reduce caregivers' burden and prevent development of burn out. Young age and longer caregiving time have been reported in literature to be related to higher caregivers' burden.$^{10,15}$ High caregivers' burden among the employed caregivers could result from poor remuneration and high level of underemployment in the study area. Also, caregivers with their ill relatives on admission were expected to suffer higher burden. There is need for further research into why higher education was found to be associated with high caregivers' burden.

Being a cross-sectional study from a center, the findings of this study might be difficult to generalize and no causeeffect relationship could be established. Nevertheless, it provides useful information that will guide policy to reduce caregiver burden of family caregivers and make caregiving worthwhile.

\section{Conclusions}

This study documents experiences of family caregivers of ophthalmic patients in a major university teaching hospital in south-west Nigeria. It reports that family caregivers suffer caregiving burden and identifies factors determining burden, coping strategies and ways to reduce this burden. Hence, family caregivers need more assistance from the health care institutions and community, including policy makers, so that they can cope with the burden. They should be encouraged to enrol in the social health insurance scheme to reduce out of pocket payment of hospital bills.

\section{Conflicts of interest}

The authors disclose no potential conflict of interest and they received no funding for this study.

\section{References}

1. Khan Z, Braich P.S, Rahim K, Rayat J.S, Xing L, Iqbal M, et al.Burden and depression among caregivers of visually impaired patients in a Canadian population. Adv Med. 2016; 2016:1-8. http://dx.doi. org/10.1155/2016/4683427.

2. Moschos MM. Physiology and Psychology of Vision and Its Disorders: A Review. Med Hypothesis Discov Innov Ophthalmol. 2014; 3(3): 83-90.

3. Swaroop N, Ravi N, Goud BR, Archana M, Pius TM, Pal A, et al.Burden among caregivers of mentally- ill patients: A rural community - based study. Int J Res Dev Health. 2013; 1(2): 29-35.

4. Vu HTV, Keeffe JE, McCarty CA, Taylor HR. Impact of unilateral and bilateral vision loss on quality of life. Br J Ophthalmol. 2005;89(3):360363. doi: 10.1136/bjo.2004.047498.

5. Hinds A, Sinclair A, Park J, Suttie A, Patterson H, Macdonald M. Impact of an interdisciplinary low vision service on the quality of life of low vision patients. Br J Ophthalmol. 2003;87(11):1391-1396.

6. Kim H, Chang M, Rose K, Kim S. Predictors of caregiver burden in caregivers of individuals with dementia. J Adv Nursing. 2012; 68(4): 846855. doi: 10.1111/j.1365-2648.2011.05787.x

7. iegand H, Kish L. Survey sampling. John Wiley \& Sons, inc., New York, London 1965, IX + 643 S., 31 Abb., 56 tab., Preis 83 s. Biom Z. 1968;10(1):88-89. https://doi.org/10.1002/bimj.19680100122

8. Akpan-Idiok PA, Anarado AN. Perception of burden of caregiving by informal caregivers of cancer patients attending University of Calabar Teaching Hospital, Calabar, Nigeria. Pan Afr Med J. 2014; 18:(159). doi: 10.11604/pamj.2014.18.159.2995

9. Nuhu FT, Yusuf AJ, Akinbiyi A, Fawole JO, Babalola OJ, Sulaiman ZT, et al. The burden experienced by family caregivers of patients with epilepsy attending the government psychiatric hospital, Kaduna, Nigeria. Pan Afr Med J. 2010; 5:16. doi: 10.11604/pamj.2010.5.16.211

10. Zarit SH, Reever KE, Bach-Peterson J. Relatives of the impaired elderly: Correlates of feelings of burden. Gerontologist. 1980;20(6):649655. https://doi.org/10.1093/geront/20.6.649

11. Glajchen M. The emerging role and needs of family caregivers in cancer care. J Support Oncol. 2004;2(2):145-155.

12. Gaston-Johansson F, Lachica EM, Fall-Dickson JM, Kennedy MJ. Psychological distress, fatigue, burden of care, and quality of life in primary caregivers of patients with breast cancer undergoing autologous bone marrow transplantation. Oncol Nurs Forum. 2004; 31(6):1161-1169. doi: 10.1188/04.ONF.1161-1169

13. Breitbart W. Spirituality and meaning in supportive care: Spirituality and meaning-centered group psychotherapy interventions in advanced cancer. Support Care Cancer. 2002;10(4):272-280. doi: 10.1007/ s005200100289

14. Lin HR, Bauer-Wu MS. Psycho-spiritual well-being in patients with advanced cancer: An integrative review of the literature. J Adv Nurs. 2003;44(1):69-80. 
15. Wong MS, Chan SW. The experiences of Chinese family members of terminally ill patients: A qualitative study. J Clin Nurs. 2007;16(12):2357-2364. doi: 10.1111/j.1365-2702.2007.01943.x

16. Marcus F. Strengthening family supports. Cancer and the family. Cancer. 1990; 65(3 Suppl): 752-359. doi: 10.1002/1097-0142
17. Hassan MB, Olowookere SA, Adeleke NA, Akinleye CA, Adepoju EG. Patterns of presentations at a free eye clinic in an urban state hospital. Niger J Clin Pract. 2013; 16 (2): 145-148. doi: 10.4103/11193077.110124 